\title{
ARTIGO
}

\section{“CIÊNCIA SEM FRONTEIRAS" COMO ACONTECIMENTO DISCURSIVO E DISPOSITIVO DE PODER/SABER}

\author{
Carina Merkle Lingnau - (https://orcid.org/0000-0002- 8469-3961) * \\ Universidade Tecnológica Federal do Paraná, Francisco Beltrão, Paraná, Brasil \\ Pedro Navarro - (https://orcid.org/0000-0003-3267-4985) * * \\ Universidade Tecnológica Federal do Paraná, Francisco Beltrão, Paraná, Brasil
}

RESUMO: A ideia de que internacionalizar a educação é tarefa da qual o ensino superior no país não pode escapar mobiliza as discussões realizadas ao longo deste artigo. Assim, a partir da premissa de que o chamado Programa Ciência sem Fronteiras se configura como um dispositivo de poder/saber, refletimos sobre as regularidades discursivas e os efeitos de poder vinculados a um conjunto de enunciados que tem como referencial a internacionalização da educação. Primeiramente, discutimos o programa como acontecimento discursivo e dispositivo de governamentalidade; em seguida, analisamos sequências enunciativas retiradas de um arquivo mais abrangente, composto por documentos e entrevistas feitas a sujeitos que tiveram uma experiência educacional com esse programa. As discussões encontram-se calcadas em levantamento bibliográfico, pesquisa documental e entrevistas narrativas (BAUER \& GASKEL, 2002), Também valemo-nos do método arquegenealógico, com base em Foucault (1999, 2008, 2014, 2015), bem como Deleuze (2011), Veyne (2011) e Navarro (2004, 2011, 2015).

Palavras-chave: Discurso; Acontecimento; Dispositivo; Governamentalidade; Programa Ciência sem Fronteiras.

\section{"SCIENCE WITHOUT BORDERS" AS A DISCOURSIVE EVENT AND POWER/KNOWLEDGE DEVICE}

ABSTRACT: The idea that internationalizing education is a task that higher education in Brazil can't escape from mobilizes discussions carried out throughout this article. Based on the premise that Science Without Borders Program is configured as a power/knowledge device, we reflect on discursive

\footnotetext{
* Doutora em Letras pela Universidade Estadual de Maringá (UEM). Professora do Departamento Acadêmico de Ciências Humanas, Letras e Artes (DAHLA) da Universidade Tecnológica Federal do Paraná (UTFPR). Membro do grupo de pesquisa Discursos sobre trabalho, tecnologia e identidades.

Email: < carinadebeltrao@gmail.com>.

* * Doutor em Linguística e Língua Portuguesa pela Universidade Estadual Paulista (UNESP) de Araraquara, SP. Professor associado do Departamento de Letras e do Programa de Pós-graduação em Letras da Universidade Estadual de Maringá, PR. Líder do grupo de pesquisa Grupo de Estudos Foucaultianos da UEM (GEF). Email:<navarro.pl@gmail.com>.
} 
regularities and power effects linked to a set of statements that have the internationalization of education as a reference. At first, we discussed the program as a discursive event and as a device of governmentality; afterwards, we analyzed some enunciative sequences taken from a more comprehensive database, composed of documents and interviews done to subjects who had educational experience with this program. The discussions are based on bibliographical research, documentary research and narrative interviews (BAUER \& GASKEL, 2002). In addition to the discursive analysis of this material, we use the archegenealogical method developed by Foucault $(1999,2008,2014,2015)$, as well as Deleuze (2011), Veyne (2011) and Navarro (2004, 2011, 2015).

Keywords: Discourse; Event; Device; Governmentality; Science Without Borders Program.

\section{INTRODUÇÃO}

A finalidade deste artigo é problematizar o Programa Ciências sem Fronteiras (doravante CsF) como acontecimento discursivo e dispositivo de poder/saber que se projeta sobre os sujeitos da educação nele envolvidos. Debruçamo-nos, também, sobre um conjunto de enunciados que gravitam em torno desse acontecimento e obtém dele seus sentidos, com vistas a descrever e a compreender os processos de subjetivação que têm lugar nessa produção discursiva. Tais enunciados foram ditos no interior de uma instituição, no caso a Universidade Tecnológica Federal do Paraná, campus de Francisco Beltrão (doravante UTFPR-FB), o que lhes garante possibilidade material de existência no interior de um "arquivo" (FOUCAULT, 2014) mais abrangente sobre as políticas públicas de educação no Brasil.

De acordo com Foucault (2008, p.12), a verdade "é deste mundo; ela é produzida nele graças a múltiplas coerções e nele produz efeitos regulamentados de poder. Cada sociedade tem seu regime de verdade". Assim, o regime de verdade atual parece autorizar a internacionalização como uma verdade que produz um efeito de necessidade em vários campos do saber. No movimento descontínuo na história, os feixes de relações vão se ligando à internacionalização e é nessa tensão que acontece o $\mathrm{CsF}$.

O programa CsF foi instituído pelo decreto ${ }^{1}$ n. 7642 de 13 de dezembro de 2011. No primeiro artigo desse documento oficial está enunciado que

fica instituído o Programa Ciência sem Fronteiras, com o objetivo de propiciar a formação e capacitação de pessoas com elevada qualificação em universidades, instituições de educação profissional e tecnológica, e centros de pesquisa 
estrangeiros de excelência, além de atrair para o Brasil jovens talentos e pesquisadores estrangeiros de elevada qualificação, em áreas de conhecimento definidas como prioritárias.

No que diz respeito às áreas contempladas pelo Programa CsF, a portaria interministerial no 1 , de 9 de janeiro de 2013 institui as áreas prioritárias de atuação do Programa CsF:

I - engenharias e demais áreas tecnológicas; II - ciências exatas e da terra; III - biologia, ciências biomédicas e da saúde; IV - computação e tecnologias da informação; V - tecnologia aeroespacial; VI - fármacos; VII - produção agrícola sustentável; VIII - petróleo, gás e carvão mineral; IX - energias renováveis; X tecnologia mineral; XI - biotecnologia; XII - nanotecnologia e novos materiais; XIII - tecnologias de prevenção e mitigação de desastres naturais; XIV biodiversidade e bioprospecção; XV - ciências do mar; XVI - indústria criativa; XVII - novas tecnologias de engenharia construtiva; e XVIII - formação de tecnólogos (BRASIL, 2013).

O CsF apresenta em seu sítio "modalidade graduação" os seguintes requisitos para a participação no programa: ser brasileiro ou naturalizado; estar regularmente matriculado em IES no Brasil em cursos relacionados às áreas prioritárias do $\mathrm{CsF}$; ter sido classificado com nota do Exame Nacional do Ensino Médio (ENEM), com no mínimo 600 pontos considerando os testes aplicados a partir de 2009; possuir bom desempenho acadêmico; ter concluído no mínimo $20 \%$ e no máximo $90 \%$ do currículo previsto para o curso de graduação.

Ainda nesse mesmo sítio é informado que os benefícios ${ }^{3}$ do bolsista são os seguintes: mensalidade de bolsa (US\$870,00), auxílio instalação (US\$ 1320,00), auxílio material didático (US\$ 1000,00), auxílio deslocamento (US\$1604,00), e seguro saúde (US\$1080,00). A duração desses benefícios é de 12 meses, podendo estender-se até 18 meses quando incluir curso de idioma. O prazo de curso de idioma é apresentado na chamada, variando de país e do acordo estabelecido com as universidades no exterior.

Entre os objetivos que encontramos no sítio, são listados: investir na formação de pessoal altamente qualificado nas competências e habilidades necessárias para o avanço da sociedade do conhecimento; aumentar a presença de pesquisadores e estudantes de vários níveis em instituições de excelência no exterior; promover a inserção internacional das instituições brasileiras pela abertura de oportunidades semelhantes para cientistas e estudantes estrangeiros; ampliar o conhecimento inovador de pessoal das indústrias tecnológicas; atrair jovens talentos científicos e investigadores altamente qualificados para trabalhar no Brasil. 
Os critérios e os objetivos do CsF sinalizam que o programa encontra-se inserido em um momento histórico cuja "positividade"4 (FOUCAULT, 2014) aponta para o fato de que os indivíduos estão mergulhados em um emaranhado de linhas conectadas entre países do globo terrestre, em meio a um tom emergencial que ecoa internacionalismo para todos os lados, instituições que se conectam umas com as outras, uma urgência em enviar e receber pessoas de todos os cantos do mundo para universidades, empresas, hospitais, mídia. Essa tendência, que parece orientar um movimento crescente de globalizar e internacionalizar as diversas instâncias do poder/ saber tangencia as relações construindo necessidades e verdades que, lentamente, se solidificam e naturalizam-se, como se não houvesse outra possibilidade a não ser instituir programas como o CsF e mostrar para a sociedade que esse é o caminho a seguir.

\section{ACONTECIMENTO DISCURSIVO E O PROGRAMA CIÊNCIA SEM FRONTEIRAS}

Um aspecto importante a ser considerado para que o discurso se manifeste com valor de acontecimento nas análises de cunho histórico-discursiva é o trabalho de monumentalizar os documentos históricos: enquanto a história tradicional transforma os monumentos do passado em documentos, por meio dos quais o discurso se empenha em reconstituir aquilo que os homens fizeram ou decidiram, ou em determinar o que é passado e o que apenas deixa rastros, a história serial monumentaliza o documento, constitui séries, define seus elementos e limites, descobre outro tipo de relação que lhes são específicas e a lei que as rege. A análise discursiva que monumentaliza seus documentos descreve as relações entre as diferentes séries, para constituir, assim, séries de séries ou "quadro".

Um exemplo desse trabalho de monumentalização documental, que faz o discurso funcionar com valor de acontecimento em determinado saber, ao longo de um período histórico, é dado por Foucault (2015a) no texto de "A vida dos homens infames", quando ele monumentaliza aquela série documental arquivada há tanto tempo, as chamadas lettre de cachet, e faz uma descrição que nos mostra qual o funcionamento do poder na ordem de um saber político.

Em sua aula inaugural no Collège de France, Foucault (2014a) afirma que acontecimento não é uma coisa, um objeto consistente, não é substância, acidente, qualidade ou processo. Não é também da ordem dos corpos, mas nem por isso deixa de ter uma materialidade, já que é justamente na materialidade que ele tem efeito e lugar. $\mathrm{O}$ 
acontecimento não apresenta uma unidade material, porque se produz numa dispersão material. Ele é feito de cesuras que dispersam o sujeito em uma pluralidade de posições e de funções; é um corte ou recorte que se realiza livremente na realidade, um acúmulo ou uma seleção de elementos.

$\mathrm{Na}$ esteira dessas definições, o CsF pode ser visto como um acontecimento na ordem de um saber político-educacional, uma vez que sua instalação advém de uma política pública governamental que visava à formação complementar de indivíduos fora de seu país de origem. Eis um primeiro ponto a ser considerado para as análises aqui empreendidas. Outra questão acerca da ideia de acontecimento relacionada com o referido programa educacional tem a ver com o fato de que, sendo acontecimento dessa magnitude, estratos de acontecimento podem dele ser extraídos, talvez com uma visibilidade menor, mas que possuem (carregam) efeitos poder/saber nesse "domínio associativo" (FOUCAULT, 2014) no interior do qual a internacionalização da educação parece figurar como a regularidade que vincula os dizeres a uma formação discursiva.

Daí a necessidade de as análises discursivas centrarem-se nos enunciados efetivamente ditos e/ou escritos pelos homens, haja vista que tais enunciados encontram sua condição de existência material, por exemplo, nas instituições em que são proferidos. É o que analisa Foucault (2014), ao tratar do lugar de onde o sujeito obtém seu discurso como parte integrante das regras de formação das modalidades enunciativas. No caso sob investigação, esse lugar de onde se fala é determinante dos processos de objetivação da educação, bem como dos processos de subjetivação dos indivíduos sobre os quais pesam os efeitos desse tipo de governo (desse tipo de política governamental para a educação).

No caminho das reflexões aqui adotado, vale resgatar a célebre definição do filósofo francês, para quem "um enunciado é sempre um acontecimento que nem a língua nem o sentido podem esgotar inteiramente" (FOUCAULT, 2015, p. 34). A esse respeito, Voss e Navarro (2013, p. 97) afirmam que

o método arqueológico trata de verificar o estatuto de acontecimento discursivo que o enunciado desempenha no arquivo (conjunto de todos os enunciados existentes). Os movimentos da história se desenham pelas séries de enunciados postos lado a lado e representando, cada um deles, um acontecimento discursivo.

Nesse movimento da história da educação brasileira, buscamos no arquivo o estatuto de acontecimento para o evento CsF. Veyne (2011, p. 45) afirma que, "para um foucaultiano, [...] a sociedade, 
longe de ser o princípio ou o termo de toda explicação, precisa ela própria ser explicada”. A sociedade contemporânea, por si só, não dá conta de explicar discursos como o da internacionalização. Foucault (2008, 2014, 2014a) propõe olhar para a história como uma história serial e captar rupturas que criem efeitos de verdade para suas versões dos enunciados.

Revel (2005, p. 14) analisa que "é por ocasião de uma discussão com os historiadores que Foucault dá a definição de acontecimentalização: "não uma história acontecimental, mas a tomada de consciência das rupturas da evidência induzidas por certos fatos". Visualizar o CsF como acontecimentalização exerce um papel de romper com práticas de internacionalização vigentes nas IES até então. Foucault (2015, p.248) considera que "é preciso considerar o discurso como uma série de acontecimentos, como acontecimentos políticos, através dos quais o poder é vinculado e orientado". O CsF foi um acontecimento advindo de um programa vinculado ao governo federal que orientou e encaminhou o processo discursivo em torno desse enunciado.

Foucault (2015a, p. 98-99) elucida a relação entre arquivo e acontecimento, da seguinte forma:

chamarei de arquivo não a totalidade de textos que foram conservados por
uma civilização, [...] mas o jogo de regras que em uma cultura, determinam o
aparecimento e o desaparecimento de enunciados, sua permanência e seu
apagamento, sua existência paradoxal de acontecimentos e de coisas.

É nesse tempo globalizado, em que a função sujeito é preenchida por essa tendência fragmentada das relações, é nessa redoma das nações inventadas que os enunciados fronteiras e sem fronteiras aparecem e se dispersam nas tensões dos cotidianos nacionais e internacionais. Para Foucault (2014, p.113)

o sujeito do enunciado é uma função determinada, mas não forçosamente a mesma de um enunciado a outro; na medida em que é uma função vazia, podendo ser exercida por indivíduos, até certo ponto, indiferentes, quando chegam a formular o enunciado: e na medida em que um único e mesmo indivíduo pode ocupar, alternadamente, em uma série de enunciados, diferentes posições e assumir o papel de diferentes sujeitos.

Assim, esse lugar dito vazio é preenchido pela noção de sujeito como posição, uma posição que assume quando se vincula ao CsF, quando aceita se enquadrar nos requisitos necessários à candidatura $\mathrm{a}$ uma vaga, quando assume, em seu discurso, as benesses do programa ou mesmo quando a ele faz resistência.

Não podemos deixar de lembrar que, em um contexto de crise e de fragmentação das identidades, o CsF como dispositivo parece 
ensejar oferecer um sentimento de identidade unificada aos sujeitos da educação, quando os quer enquadrar em um tipo de governo que tende a fazer vivenciar uma língua e uma cultura outras, sem que se leve em conta as particularidades de cada aprendiz. Nesse sentido, resgatamos Hall (1997), que estabelece relação com Foucault (2014), ao se referir ao sujeito não como pleno, mas como uma função que é modificada frequentemente. Assim, para que um acontecimento discursivo surja como tal, é preciso que seja formulado, que um sujeito pense e expresse tal discurso nessa história descontínua e serialista que descentraliza o homem. Seguindo essa linha de pensamento, associamos a internacionalização com a possibilidade de ruptura do padrão de atividades relacionadas somente ao país e a busca pela verdade de uma constante necessidade de troca de experiências entre os países do mundo. A relação entre a construção dessa verdade e o dispositivo de governamentalidade é o que objetivamos discutir na seção seguinte, tendo como base a experiência do CsF na UTFPR-FB.

\section{2. $O$ DISPOSITIVO DE GOVERNAMENTALIDADE EM EXERCÍCIO NA UTFPR-FB: UM BREVE ESTUDO DE CASO}

Como exposto anteriormente, o lugar de onde o sujeito obtém seu discurso e de onde falam é algo constitutivo das regras de formação discursiva, assim como do poder que ali se exerce. Isso nos leva a considerar o tipo de dispositivo de governamentalidade que tem lugar de existência na UTFPR, fundamentados em Foucault (1999, 2008, 2014), Agamben (2011), Veyne (2011) e Deleuze (2011). Relacionamos esse aspecto às sequências enunciativas (doravante SEs) que, ao tomarem como objeto de discurso o ensino técnico e a instituição, dão visibilidade ao atravessamento do dispositivo de governamentalidade aliado à educação superior fora do país de origem. Buscamos, assim, na história serial os documentos/ monumentos em relação ao ensino técnico e à UTFPR-FB, analisando, de um ponto de vista arquegenealógico, as relações entre eles para elencar as práticas especificadas recortadas nas SEs desse interminável elemento do arquivo.

Tendo em vista que o trabalho genealógico nos aproxima dos efeitos produzidos pelos dispositivos que articulam as relações entre o poder e o saber, traçamos o que chamamos de arquegenealogia da UTFPR-FB e trabalhamos com o que Foucault (2008, p. 15) denomina genealogia, considerando que ela é "cinza; ela é meticulosa e pacientemente documentária. Ela trabalha com pergaminhos embaralhados, riscados, várias vezes reescritos". 
Para defender a tese de que o CsF é um acontecimento discursivo cuja condição de existência se dá no interior de um dispositivo de poder/saber de cunho político-educacional, recorremos a Foucault (2008, p. 244), para quem o "discurso pode aparecer como programa de uma instituição [...] como um tipo de formação que, em um determinado momento histórico, teve como função principal responder a uma urgência". Nessa mesma direção, Veyne (2011, p. 166) afirma que "um certo regime de verdade e certas práticas formam assim um dispositivo de poder/saber que inscreve no real o que não existe, submetendo-o ainda à divisão do verdadeiro e do falso". Ainda sobre a noção de dispositivo, Agamben (2011, p. 256) explica que

\footnotetext{
o termo dispositivo nomeia aquilo no que e pelo que se realiza a atividade pura do governo sem a mediação fundada no ser. É por isto que os dispositivos devem sempre implicar um processo de subjetivação, devem produzir um sujeito.
}

Essas citações nos autorizam a afirmar que o CsF acaba lançando efeitos do verdadeiro e falso sobre o programa brasileiro que envia alunos das instituições de ensino superior (doravante IES) brasileiras para o exterior. A positividade do momento histórico em que o dispositivo CsF está em evidência permite os discursos da internacionalização das IES.

O CsF assume um valor de acontecimento e de dispositivo de governamentalidade nas IES brasileiras e do exterior, ao ser identificado como um programa do governo federal brasileiro que tentou responder à urgência do regime de verdade sobre a internacionalização firmado no momento histórico em que estamos inseridos. Ainda nessa mesma direção, podemos afirmar, também, que o CsF é um dispositivo de poder/saber que, ao se relacionar com os egressos e envolvidos no CsF, cria efeitos de verdade sobre tais sujeitos em discursos que se dispersam em campos do saber, tais como: educação, mídia, economia, relações internacionais.

Nesse sentido, o dispositivo CsF torna os indivíduos em sujeitos egressos de uma educação internacionalizada, isto é, os faz falar dessa posição discursiva, à medida em que põe em funcionamento processos de subjetivação que posicionam esses corpos em instituições acadêmicas, no mercado de trabalho, nas relações cotidianas e que são marcados pelo dispositivo que projetou um lampejo de novidade. Esse sujeito já não é mais um simples acadêmico das IES, ele é um egresso do CsF, um sujeito que foi exposto a outros dispositivos, outros processos de governamentalidade, outros acontecimentos e que retorna à instituição de origem marcado ora como sujeitado, ora como resistente à ordem do discurso vigente. Navarro (2015, p. 197) contribui com uma reflexão 
sobre uma das formas de manifestação do dispositivo, quando estabelece que "acolher o texto de $A$ ordem do Discurso como um dos momentos do pensamento de Foucault (2014a) em que o saber encontra o poder é observar uma das formas de manifestação do dispositivo".

Nesse caso, ao tratarmos o CsF como dispositivo, levamos em conta as suas formas de manifestação, mensuradas pelos pontos de vista dos egressos do programa da UTFPR-FB e dos servidores de outros campi da UTFPR, o que significa observar o alcance desse dispositivo nas manifestações encontradas nas entrevistas.

Outro importante aspecto relativo à noção de dispositivo nos é oferecido por Deleuze (2011, p. 3), que ensina que os dispositivos "têm por componentes linhas de visibilidade, linhas de enunciação, linhas de força, linhas de subjectivação, linhas de brecha, de fissura, de fractura, que se entrecruzam e se misturam”. Logo, observamos o CsF como dispositivo que visibiliza um programa de mobilidade em meio a linhas entrecruzadas de outros elementos que impulsionam o programa $\mathrm{CsF}$ a assumir um valor de acontecimento e de dispositivo de governamentalidade nas IES brasileiras e do exterior, ao ser identificado como um programa do governo federal brasileiro que tentou responder à urgência do regime de verdade sobre a internacionalização firmado no momento histórico em que estamos inseridos. A partir do dispositivo CsF, a sociedade brasileira e internacional projeta discursos sobre o programa, sobre os sujeitos produzidos pelo dispositivo, sobre as várias camadas que constituem e desconstituem o dispositivo.

Considerando que, segundo Agamben (2011, p. 249), “a palavra dispositivo é um termo decisivo na estratégia de pensamento de Foucault. Sobretudo utiliza-o a partir dos anos 1970 quando começa a se ocupar da 'governamentalidade' ou do 'governo dos homens”, damos continuidade às nossas discussões, voltamo-nos, nesse ponto do artigo, à questão da governamentalidade vinculada ao CsF.

\subsection{GOVERNO DO SUJEITO DA EDUCAÇ̃̃O INTERNACIONALIZADA PELO CSF}

Foucault (2008, p. 291-292) destaca três significados para o termo governamentalidade:

1 - o conjunto constituído pelas instituições, procedimentos, análises e reflexões, cálculos e táticas que permitem exercer esta forma bastante específica e complexa de poder, que tem por alvo a população, por forma principal de saber a economia política e por instrumentos técnicos essenciais os dispositivos de segurança.

2 - a tendência que em todo o Ocidente conduziu incessantemente, durante muito tempo, à preeminência deste tipo de poder, que se pode chamar de governo, sobre 
todos os outros - soberania, disciplina, etc. - e levou ao desenvolvimento de uma série de aparelhos específicos de governo e de um conjunto de saberes.

3 - resultado do processo através do qual o Estado de justiça da Idade Média, que se tornou nos séculos XV e XVI Estado administrativo, foi pouco a pouco governamentalizado.

Nessa acepção, tomamos o CsF como dispositivo que articula estratégias de governamentalidade em nosso tempo histórico. $\mathrm{Na}$ relação de governamentalidade e do dispositivo do CsF, motivador das relações Estado-nação e pedagogia, encontramos no sítio da $\mathrm{UTFPR}^{5}$ a seguinte informação: "a UTFPR está entre as 50 melhores instituições de ensino superior do Brasil, segundo o Ranking Universitário da Folha de São Paulo (RUF) divulgado nesta segunda-feira”. Ora, esse dado, aparentemente informativo apenas, não deixa de apontar para uma necessidade de a instituição se colocar como um instrumento a serviço da educação e capaz de gerir, supostamente com competência, a vida dos estudantes universitários. Não podemos deixar de encontrar aí uma posição enunciativa própria daquele que deseja, está imbuído da missão de governar os outros pelo governo de si.

Sobre essa análise, as palavras de Foucault (2015a, p. 288) parecem bastante oportunas:

governante pode ser chamado qualquer monarca, imperador, rei, príncipe, senhor, magistrado, prelado, juízes e semelhantes [...] de governar se lembrarão com regularidade que se diz, igualmente, governar uma casa, crianças, almas, uma província, um convento, uma ordem religiosa, uma família.

No tocante ao léxico utilizado por Foucault, Veiga-Neto (2002) mostra uma preocupação com o que ele entende como sendo o uso correto das palavras relacionadas ao termo governamentalidade, como segue: governamento ${ }^{6}$ está para governar/executar uma ação; governo está presente quando o sentido é de Governo municipal, estadual, da República; governamentalidade é adotada como tradução do conceito gouvernementalité. O detalhamento do conceito governamentalidade obtemos em Fimyar (2009, p. 38) quando ela esclarece que

ao fundir o governar (gouverner) e a mentalidade (mentalité) no neologismo governamentalidade, Foucault enfatiza a interdependência entre o exercício do governamento (práticas) e as mentalidades que sustentam tais práticas. Em outras palavras, a governamentalidade pode ser descrita como o esforço de criar sujeitos governáveis através de várias técnicas desenvolvidas de controle, normalização e moldagem das condutas das pessoas.

Para saber se a noção de governamentalidade ainda é relevante atualmente, Lemke ${ }^{7}$ ao ser entrevistado atesta que 
a noção de governamentalidade foi assumida por muitos estudiosos de diferentes países e contextos. Eles estavam à procura de um instrumento analítico que fosse capaz de explicar as transformações radicais que alteraram os regimes de bem estar nas sociedades neoliberais. Não simplesmente em termos de detecção de ideologias políticas abstratas que assumiram, mas sim em termos de realização empírica análises concretas em domínios específicos da sociedade: que racionalidades emergiram neste ou naquele campo, quais tecnologias têm substituído as mais velhas, e como exatamente eles são informados, que objetivos que pretendem atingir e quais são os meios que são colocados em prática, e assim por diante. Nestes termos, a governamentalidade revela-se uma ferramenta analítica útil, mas também instrumento muito útil para a crítica social (BAELE e LEMKE, 2008, p. 1-2).

Ao nos valermos da governamentalidade como ferramenta útil para a elaboração de crítica social e análise, lemos em Amos (2010, p. 27) que

ao pensar nas relações educativas modernas, especialmente na forma dos sistemas educacionais, é o neoinstitucionalismo ${ }^{8}$ sociológico que proporciona alguns dos mais profundos insights para o entendimento da relação entre o Estado e "seu" sistema educacional. Em outras palavras, é inegável o mérito do neoinstitucionalismo macrossociológico, fenomenológico, ao introduzir aspectos das estruturas relacionais entre a política, i.e., o Estado-nação, e a pedagogia.

Para exemplificar esse aspecto neoinstitucionalista na relação de governamentalidade e do dispositivo do $\mathrm{CsF}$ motivador das relações Estado-nação e pedagogia, retomamos a informação do sítio da UTFPR9, agora com seu desenvolvimento completo na página, na qual lemos:

a UTFPR está entre as 50 melhores instituições de ensino superior do Brasil, segundo o Ranking Universitário da Folha de São Paulo (RUF) divulgado nesta segunda-feira (19). O levantamento existe há cinco anos e classifica as universidades a partir de 5 indicadores: pesquisa, ensino, mercado, inovação e internacionalização. Em uma escala de 0 a 100, a UTFPR foi pontuada com a nota final de 65,1, calculada com as seguintes notas de cada indicador: 26,2 na Pesquisa (em esclada de 0 a 40); 24,32 no Ensino (em escala de 0 a 32); 9,72 no Mercado (em escala de 0 a 18); 1,8 na Internacionalização (em escala de 0 a 6); 3,06 na Inovação (em escala de 0 a 4); e 3,43 no Índice Geral de Cursos do MEC (em escala de 0 a 5). Já na avaliação individual por curso, destacaram-se as engeharias de Contole e Automação ( $8^{\circ}$ lugar), Mecânica $\left(11^{\circ}\right.$ lugar) e Elétrica $\left(16^{\circ}\right.$ lugar). A avaliação dessas carreiras é feita com base em uma média das notas dos cursos de todos os câmpus da UTFPR.

Assim, verificamos que os dispositivos de indicação, que têm por objetivo posicionar as IES, em diversas categorias, funcionam como estratégias de governamentalidade e justificam o interessa da instituição UTFPR em melhorar seus índices de internacionalização, com programas como o $\mathrm{CsF}$. 
Para dar prosseguimento a essas discussões, na seção seguinte centramos nossa análise na instituição de onde os sujeitos obtêm seus discursos e enunciam aquilo que consideram uma verdade sobre a educação.

\subsection{UMA PROPOSTA DE ANÁLISE ARQUEGENEALÓGICA DE DISCURSOS SOBRE EDUCAC̣ÃO E INTERNACIONALIZAÇÃO}

A proposta de análise calcada no método que se depreende dos estudos de Foucault, quando esse autor direciona seu olhar para as relações entre poder e saber nos oferece elementos para analisar as relações entre o discursivo (as entrevistas e os documentos) e as instituições envolvidas no processo.

A fim de organizar o material selecionado para o corpus discursivo, perfilamos os enunciados conforme a ordem em que aparecem na análise, utilizando a sigla SE para simbolizar a expressão sequência enunciativa, seguida da ordem numérica em que são apresentados. Demais materiais, tais como decretos, mídias, artigos de revistas foram recortados do suporte material utilizado e referenciado ao final da série descrita, utilizando o sinal gráfico parênteses.

$\mathrm{Na}$ tentativa de esboço de uma arquegenealogia dos saberes e dos jogos de poder que constituem os discursos acerca da internacionalização da ciência, vislumbramos um efeito de governamentalidade do período que a história tradicional chama de Brasil República. Consideramos as seguintes SEs:

SE1- Considerando: que o augmento constante da população das cidades exige que se facilite às classes proletarias os meios de vencer as dificuldades sempre crescentes da lueta pela existencia: que para isso se torna necessario, não só habilitar os filhos dos desfavorecidos da fortuna com o indispensavel preparo technico e intelectual, como faze-los adquirir habitos de trabalho proficuo, que os afastara da ociosidade ignorante, escola do vicio e do crime; que é um dos primeiros deveres do Governo da Republica formar codadões uteis à Nação: Decreta: Art. $1^{\circ}$. Em cada uma das capitaes dos Estados da Republica o Governo Federal manterá, por intermedio do Ministerio da Agricultura, Industria e Commercio, uma Escola de Aprendizes Artifices, destinada ao ensino profissional primario gratuito. (Decreto $\mathrm{N}^{0} 7.566$, de 23 de setembro DE 1909) ${ }^{10}$

SE2 - Com a transferência da CBAI (Comissão Brasileiro-Americana de Educação Industrial $)^{11}$ para a Escola Técnica de Curitiba, todo o material gráfico produzido pela Comissão passou a ser publicado pela gráfica da Instituição. (CBAI - sítio UTFPR)

SE3 - O estreitamento das relações entre o Brasil e os Estados Unidos dá, frequentemente, margem aos mais diferentes comentários. Não só aqui, como por certo, até naquele país amigo esse fenômeno é, também observado. Nada como o tempo para evidenciar as intenções e apresentar os fatos despidos de falsas aparências. (Nossa página: Brasil - Estados Unidos. Ano VIII, Jornal Labor ${ }^{12}$, 1947) 
SE4 - Art. 2 A UTFPR reger-se-á pelos seguintes princípios: I - ênfase na formação de recursos humanos, no âmbito da educação tecnológica, nos diferentes níveis e modalidades de ensino, para os diversos setores da economia, envolvidos nas práticas tecnológicas e na vivência com os problemas reais da sociedade, voltados, notadamente, para o desenvolvimento socioeconômico local e regional. (Lei da criação da UTFPR - Lei no 11.184, de 07 de outubro de 2005).

SE5 - Quem quiser comprar hum mulato official de Marcineiro, que sabe fazer carros e rodeiros para carroças e seges, e também exercitalo em lambica agoardente, e fazer assucar, procure seu dono, que mora em Mattacavalos, na esquina da rua dos Invalidos, na caza em que esteve o Quartel General. (Aviso - Gazeta do Rio de Janeiro $^{13}$, n.56, quarta-feira, $1^{\circ}$ de julho de 1820).

O ensino/aprendizagem para uso da força do trabalho atua como regularidade desde o Brasil República até os dias atuais. As regras que parecem levar a esse jogo discursivo, que posiciona o ensino técnico como efeito de verdade para os problemas educacionais da sociedade brasileira, são constituídas por dois elementos: relações internacionais entre Brasil e Estados Unidos da América (doravante EUA) e ensino técnico/tecnológico. As relações entre Brasil e EUA também ocorrem devido ao pós-segunda guerra mundial. Segundo Amorim (2007, p. 168)

a partir da nova conjuntura advinda com o pós-guerra, baseada na divisão do mundo em dois blocos opostos, e com o alinhamento do Brasil no bloco liderado pelos E.U.A., há um crescimento da influência estadunidense no Brasil, através da divulgação do american way of $\operatorname{life}^{14}$, tão bem expressado na ideologia do americanismo.

Entretanto, a relação entre os dois países não se constituiu de forma equivalente, ela se constrói no emaranhado das relações de poder/saber que influenciam a construção de verdade do modo de vida americano em solo brasileiro e essa influência se constrói em diversos campos.

Um dos campos é o econômico, que se posiciona como espinha dorsal dessas relações que, na dispersão, mantém as regras da educação para o trabalho manual/ técnico/tecnológico como mola propulsora ao encaminhamento educacional de parte da população brasileira.

Essa leitura das SEs na dispersão também é verificada sob o olhar dos vários escalonamentos de acontecimentos, respaldados em Foucault (2015, p. 305), para quem "a história serial permite de qualquer forma fazer aparecer diferentes estratos de acontecimentos". Assim, percebemos nas sequências alguns fatores responsáveis pela ruptura de estratégias de governamentalidade que na dispersão são identificados como: a) o processo de abolição da escravatura que rompeu com o trabalho manual/técnico escravizador, como 
está marcado na SE5. O trabalho manual/técnico é associado aos escravizados antes do processo abolicionista, mas depois esse tipo de trabalho passa a ser relacionado ao ensino técnico/tecnológico, que não necessariamente está envolvido com a produção de conhecimento, mas com a realização do trabalho. De acordo com Foucault (2008, p.141), "de uma maneira geral, os mecanismos de poder nunca foram muito estudados na história. Estudaram-se as pessoas que detiveram o poder". Dessa forma, ao desviarmos o olhar das pessoas que detiveram o poder no processo histórico e nos atentarmos para os mecanismos de poder relacionados à história serial do CsF, na perspectiva tomada a partir do corpus eleito para essa pesquisa, nos permitimos acessar outra versão, outra produção de verdade sobre as relações entre educação e internacionalização.

Outros fatores percebidos como ruptura nas SEs foram b) as políticas de colonização brasileira pós-abolição e o efeito de verdade do dispositivo do trabalho profissionalizante como um modo de manter a sociedade sob controle, tal como está expresso na SE1. Contemplamos um momento histórico em que as políticas de branqueamento no Brasil estimularam a vinda de povos não negros para ocuparem a função de sujeito trabalhadores/estudantes da área técnica como elos da sociedade de controle. c) a cooperação educacional entre Brasil e EUA representada pela Comissão Brasileira-Americana de Educação Industrial (CBAI) no Brasil, tal como enunciado nas SEs 2 e 3. Nesse cenário, o aparecimento da CBAI no Brasil consolida a forte presença dos EUA no ambiente educacional técnico brasileiro, fato esse que, na descontinuidade, ressurge, por exemplo, com o CsF, com o envio de acadêmicos para as instituições americanas.

Nesse âmbito, de acordo com Leite (2010), a UTFPR foi a primeira universidade tecnológica do Brasil e, em termos de governamentalidade, esse processo de tornar o CEFETPR em UTFPR se deu para fortalecer a tradição brasileira de 500 anos de ensino técnico/ tecnológico. Vale destacar a seguinte citação de Foucault (2015, p. 308), sobre a necessidade de "multiplicar os tipos de acontecimentos como se multiplica os tipos de duração". Nesse visada, as rupturas descritas acima apresentam uma multiplicidade de tipos de acontecimentos com durações múltiplas cujos efeitos produziram outros acontecimentos e alimentaram a trama descontínua da história serial.

Outra questão a ser pontuada é a produção gráfica de material confeccionada pelo CBAI exposto na SE2, como apostilas a serem utilizadas em cursos ministrados para formação de profissionais, além de regulamentos, normas e diretrizes que vigiam e regulam o governamento institucional. O exposto nos faz retornar a Foucault 
(1999, p. 199), quando afirma que "é o problema das grandes oficinas e das fábricas, onde se organiza um novo tipo de vigilância".

Partindo dessa citação, examinamos a proximidade das palavras de Foucault (1999) com as estratégias de governamentalidade dos governos brasileiro e americano em torno do ensino técnico e a permanência da CBAI no Brasil regulando e vigiando a produção de materiais, a condução dos professores e alunos do ensino técnico. Constatamos isso, ao observar, segundo dito nas SEs 2 e 3, que o CBAI estava presente na produção dos materiais didáticos e as relações EUA-Brasil se fortaleceram nesse sentido.

Todas essas rupturas/acontecimentos operaram efeitos de verdade diversos e novas práticas discursivas tomaram o rumo das estratégias de governamentalidade em cada época histórica representada nos recortes das SEs. Na ruptura/acontecimento do CEFETPR para UTFPR, na SE4 ainda podemos notar o dispositivo da tecnologia incorporado pelas novas estratégias de governamentalidade advindas com o dispositivo da tecnologia massificado para as populações.

Observamos que as estratégias de governamentalidade construídas a partir dessa análise arquegenealógica dos discursos sobre o CsF vão ao encontro do que Veiga-Neto (1999, p. 8) afirma:

o neoliberalismo ${ }^{15}$ dá um "adeus a Deus", na medida em que desnaturaliza as relações sociais e econômicas, ao introduzir a modelagem como um princípio segundo o qual o consumidor não é mais visto como, originalmente, um Homo œconomicus, mas é visto como um Homo manipulabilis ${ }^{16}$.

Essa análise dá visibilidade à demarcação da passagem pelo processo educacional como sinônimo de ascensão, como um efeito de verdade. Foucault $(2008$, p.12) acentua que "cada sociedade tem seu regime de verdade, sua política geral de verdade: isto é, os tipos de discurso que ela acolhe e faz funcionar como verdadeiros". Assim, o $\mathrm{CsF}$ projeta efeitos de verdade e de falsidade em camadas que podem ser mais superficiais ou mais profundas, dependendo da percepção e das relações de poder/saber em que o sujeito 'consumidor' das políticas de internacionalização está inserido.

\section{O PROGRAMA CIÊNCIA SEM FRONTEIRAS COMO DISPOSITIVO DE GOVERNAMENTALIDADE NO CSF UTFPR-FB}

O CsF pode ser considerado o maior programa de mobilidade internacional promovido pelo governo que o Brasil já teve. Segundo os seus idealizadores, foi um programa criado com o objetivo de 
"promover a consolidação, expansão e internacionalização da ciência e tecnologia, da inovação e da competitividade brasileira"17. A partir desse acontecimento na educação brasileira, o enunciado ${ }^{18}$ ciência sem fronteiras opera como dispositivo no campo educacional brasileiro e produz efeitos de governamentalidade.

Assumindo, como já anunciado, esse programa como um acontecimento discursivo na ordem de uma governamentalidade sobre os sujeitos da educação, destacamos, a seguir, alguns elementos discursivos dessa relação, a partir de trechos recortados das SEs retiradas do corpus discursivo sob análise:

SE6 - Presidenta: Olha, o Ciência sem Fronteiras vai muito bem. Eu considero um dos grandes programas do meu governo. Com ele, nós estamos levando os nossos melhores alunos para as melhores universidades do mundo. (Entrevista em rádio de 30/09/2013 com Dilma Roussef no Programa Café com a Presidenta - Ciência sem Fronteiras: conbecimento é o que move o mundo)

SE7 - E assim, é uma experiência fantástica o Ciência sem Fronteiras, é uma experiência em que o governo viu uma oportunidade de levar... Eu acho que esse programa não fez distinção de classe econômica ou de classe social, ou pelo seu coeficiente dentro da universidade.

SE8 - Então a ideia do Ciência sem Fronteiras é uma ideia extremamente positiva, nunca na história desse país teve um outro programa assim, tem que começar reconhecendo isso.

SE9 - Talvez valesse a pena lembrar que quando os nossos estudantes do Ciência sem Fronteiras deixam o Brasil para estudar nos diversos países o Governo Brasileiro está pagando, seja as anuidades na escola, seja uma bolsa de estudo. Então veja que o país acolhedor está ganhando duplamente: ele o valor das anuidades pagas pelo Governo Brasileiro e a sua bolsa de estudo porque você até certo ponto investe no país para comprar os serviços necessários para sua sobrevivência. (Aula pública Ópera Mundi, Câmpus UNESP Bauru - TVUNESP socióloga Manolita Correia Lima - publicado em 05 de maio de 2014 sobre $A$ mobilidade acadêmica é a parte mais visivel da internacionalização)

SE10 - Por que a gente ao invés de colocar todo esse montante de dinheiro no exterior, não fizemos priorizações pra investir esse dinheiro nas nossas universidades, nos nossos centros de pesquisa, e atraindo mais pesquisadores estrangeiros, não estou dizendo que o programa não deveria ter acontecido, mas ele poderia ter sido $10 \%$ ou $20 \%$ do que foi, e continuado que hoje poderia estar crescendo e não regredindo... É estranho que um país mande tanta gente e depois não tenha dinheiro para mandar mais ninguém, a educação superior é um business, e eles viram nos alunos brasileiros oportunidade de ter mais dinheiro e foi uma boa oportunidade para eles. No momento em que esse dinheiro deixar de existir eles vão focar os 
esforços em outros lugares, quando voltar a ter, vão voltar a ser amigos de novo, isso eu não tenho nenhuma dúvida (Programa 'Ensino Superior' da UNIVESP TV com análise de Marcelo Knobel do Programa Ciência sem Fronteiras - publicado em 07 de março de 2016).

SE11 - Capítulo VI - Vida do estudante Brazileiro - Despezas - Lucta com o frio e o calor - Contrastes de temperatura durante o anno letcivo - Theatros, Prelecções e reuniões familiares - Cartas de recomendação. Parecerá fora de propósito nesta série de artigos alludir aos assumptos com a epigraphe acima, porém tal é a curiosidade de muitos que tiveram e ainda tem filhos estudando naquele paiz que eu de bom grado accedo aos seus desejos. Os jovens Brazileiros que vão para os Estados-Unidos (é quasi sempre regra invariavel) levam comsigo uma carta de credito de modo que, quando alli estabelecidos, possam obter uma quantia marcada mensalmente em New-York ou em qualquer cidade dos Estados-Unidos, sem ser preciso saccarem todos os mezes contra os seus correspondentes no Brazil. (Estados-Unidos e norte-americanos acompanhado de algumas considerações sobre a immigração chineza no Imperio do Brazil. /livro escrito por José Custódio Alves de Lima ${ }^{19}$, 1886).

SE12 - A grande nação norte-americana, incontestavelmente, a mais poderosa do mundo no instante histórico ${ }^{20}$ que atravessamos, tem revelado um elevado grau de interesse humano na solução dos problemas internacionais. As nossas escolas técnicas foram brindadas com elevado número de bolsas de estudo. Não podemos deixar de citar e aplaudir a ação decisiva da direção da CBAI que possibilitou a realização desse velho sonho de muitos estudiosos brasileiros. Da Escola Técnica de Curitiba partiram primeiramente dois mestres. Recentemente partiu para a terra de “Tio San” o nosso diretor dr. Lauro Wilhem. (Jornal Labor -órgão oficial da Escola Técnica de Curitiba, n.19 de novembro, Curitiba, 1947).

SE13 - As universidades brasileiras têm quatro grandes desafios: a questão do financiamento, a questão da qualidade, a questão do acesso social e a questão da internacionalização. É justamente na questão da internacionalização, que eu, Pillati e Vanessa, compomos uma chapa tentando orientar o futuro desta instituição para uma universidade de classe mundial. (Os desafios das universidades brasileiras - Vídeo ${ }^{21}$ da campanha 2016 para reitor UTFPR, chapa Pillati e Vanessa Rumo à classe mundial. Publicado em 08 abr 2016).

SE14 - Em 1974, a Capes mantinha mil bolsistas no país e apenas 70 no exterior. No final da década, as concessões saltaram para 13 mil no Brasil e 1.200 no exterior. Nos últimos anos, o crescimento tem sido recorde. A coordenação chegou à marca dos 30 mil bolsistas em 2007 e já alcançou 58.107 em 2010 (CAPES 60 anos - Revista comemorativa, julho/2011).

A regularidade das SEs está voltada para a importância do programa $\mathrm{CsF}$ na educação brasileira representada nas SEs 6, 7, 8 e 10. Essas regularidades apontam para o que Foucault (2014, p. 66) discute, a saber: "é preciso reconhecer, agora, que não é nem 
pelo recurso a um sujeito transcendental nem pelo recurso a uma subjetividade psicológica que se deve definir o regime de suas enunciações". Portanto, não é pela interpretação dos fatos, mas pelos enunciados que essa regularidade dissemina o discurso de que a internacionalização é uma variável que está presente como possibilidade para o crescimento das IES brasileiras.

A SE13 demonstra comprometimento da chapa concorrente à reitoria com a internacionalização, visto como enunciado centralizador, que orientará o futuro da universidade para a classe mundial, para a relação globalizada com os países. No tocante a esse aspecto, Foucault (2014a, p. 48) afirma que "é preciso questionar nossa vontade de verdade; restituir ao discurso seu caráter de acontecimento; suspender, enfim, a soberania do significante". Consequentemente é preciso questionar essa vontade de estabelecer um lema que destina uma IES às relações com outros países. Quanto a essa vontade de verdade que parece fortalecer a internacionalização das IES como realidade incontestável Sargentini (2015, p. 26) afirma que "para se estudar um dispositivo, vários gestos são necessários, dentre eles desnaturalizar aquilo que se põe como assentado na história”.

Dessa forma, na tentativa de desnaturalizar essa verdade observamos outro aspecto que se encontra como regularidade: o valor econômico, o custo de se manter e ser mantido nos EUA que está presente nas SEs 9, 10 e 11. Nas SEs 9 e 10 o momento histórico é atual retomando o acontecimento da ida de alunos brasileiros para os EUA, enquanto a SE11 já tem em seu texto a relação Brasil-EUA e mobilidade 'pague você mesmo'. Sequência essa que se encontra em um momento em que não era natural se ter centenas de discentes brasileiros estudando em universidades norte-americanas às custas do governo brasileiro.

Nesse contexto, ao relacionar poder/saber, Foucault (2008, p. 141-142) assevera que "é preciso ser muito ingênuo para imaginar que é no mandarim universitário que culminam os efeitos de poder ligado ao saber". Ao que percebemos, o campo político/econômico, no caso do CsF, acentua efeitos de poder mais evidentes do que o campo educacional. Verificamos isso também na SE12 mostra outra faceta da relação Brasil-EUA. Ela situa a ruptura do momento socioeconômico pós-guerra e anuncia estratégias de governamentalidade relacionadas à mão de obra especializada e retomada econômica no país.

A partir da SE11, é possível observar o vínculo Brasil-EUA no sentido de governamento, enquanto EUA e China encontram-se numa aproximação através do programa 100,000 Strong China ${ }^{22}$, o qual estabelece relação EUA em direção à China, com o objetivo de enviar estudantes norte-americanos para estudarem na China. Nas 
SEs 9, 10 e 14, a regularidade é o uso das bolsas pela CAPES, mas a diferença desse uso é a discrepância entre os dados históricos da SE14 que evidenciam a distribuição gradativa das bolsas ligadas à pós-graduação brasileira, enquanto na SE9 e SE10 a discussão gira em torno do investimento realizado em bolsas movimentando recursos financeiros direcionados ao exterior.

A questão dos não ditos fica em torno dos motivos sobre a criação do programa CsF, a regularidade circula em um discurso de importância e de oportunidade para os estudantes das IES brasileiras, porém nenhum dos entrevistados provocou o questionamento, uma vez que o CsF foi implementado.

Nos enunciados efetivamente ditos nas entrevistas realizadas por discentes e servidores da UTFPR, não houve questionamento por conta dos motivos do programa e seus efeitos. Esse silêncio pode indicar mais um efeito das estratégias de governamentalidade, efeito esse descrito, com base nessa análise arquegenealógica de discursos sobre a internacionalização da educação, a partir da qual observamos suas regularidades em termos de posição discursiva e em relação aos seus efeitos de poder sobre os sujeitos afetos a esse programa. Nesse contexto, elegemos as palavras de Sargentini (2015, p. 21), quando pontua que "fazer a análise de um regime de práticas lhe permitirá ver o modo como um dispositivo erige-se sustentado por uma rede de elementos".

Nesse sentido, o dispositivo CsF dissemina em sua rede de elementos o discurso de que a internacionalização é uma variável que está presente como possibilidade para o crescimento das IES brasileiras.

\section{CONCLUSÃO}

A partir da discussão teórica e análise vista através das lentes da história serial das SEs acima, percebemos que a singularidade do CsF como acontecimento está cercada pelo discurso da globalização que ecoa o discurso da internacionalização nas IES. Isso repercute nos programas do governo federal brasileiro que instituem o acontecimento CsF.

A partir desse acontecimento, as universidades brasileiras se inserem no mundo globalizado e levam o nome das instituições brasileiras para vários países do mundo, o que reverbera o regime de verdade sobre a internacionalização que torna possível o acontecimento CsF.

Historicamente, a questão do ensino técnico/tecnológico está presente como regularidade desde o Brasil República até os dias 
atuais. O programa $\mathrm{CsF}$ acontece a partir das ligações entre Brasil e Estados Unidos e ensino técnico/tecnológico. Esse acontecimento também pode ser considerado dispositivo de governamentalidade na medida em que exerce efeitos de verdade e novas práticas discursivas são utilizadas em meio a estratégias de governamentalidade.

Verificamos que existe silêncio nas sequências analisadas em relação aos motivos do programa e seus efeitos. Esse silêncio pode indicar mais um efeito dos dispositivos de governamentalidade em relação à arquegenealogia e seu efeito disciplinar ao nos aproximarmos da história serial e descortinarmos estratos de acontecimentos a partir do CsF como dispositivo de governamentalidade.

Assim, nas relações de poder/saber, reafirmamos que as verdades construídas nesse corpus mostram o CsF como acontecimento e dispositivo, o que gera efeitos na academia e na sociedade globalizada de uma ordem que detecta um acadêmico interessado em experiências fora de seu país, um acadêmico que, no "pacote" de dispositivos de seu tempo, recebe o guia das necessidades do momento, como conhecimento e fluência em línguas estrangeiras, um consumidor da sociedade da informação imerso no movimento midiático e tecnológico que, através das redes de estratégias de governamentalidade atravessado por vários campos do saber, percebe em seu corpo e mente, docilizados, programas de mobilidade como o CsF como algo vindo de um sistema biopolítico que pretende conduzir a internacionalização das IES.

\section{AGRADECIMENTOS}

Agradecemos a todas e todos que foram entrevistados para essa pesquisa.

\section{REFERÊNCIAS}

AGAMBEN, G. ¿Qué es un dispositivo? Sociológica, año 26, número 73, mayo-agosto de 2011.

AMORIM, M. L. O surgimento da Comissão Brasileiro-Americana de Educação Industrial (CBAI). História da Educação (UFPel), v. 11, p. 149-171, 2007.

AMOS, K. Governança e governamentalidade: relação e relevância de dois conceitos científico-sociais proeminentes na educação comparada. Educ. Pesqui, v. 36, n. spe. São Paulo, Apr. 2010.

BAELE, S., LEMKE, T. An interview with Thomas Lemke: Foucault Today. On the theoretical relevance of Foucauldian concepts of "governmentality" and "biopolitics", Emulations, v. 2, n 4, mai. 2008. Disponível em: http://www.revue-emulations.org/ articles/lemke.pdf. Acesso em: 27 out. 2016. 
BAUER, M. W; GASKEL, G. Pesquisa qualitativa com texto, imagem e som: um manual prático I. Tradução de Pedrinho A. Guareschi. - Petrópolis, RJ: Vozes, 2002.

DELEuZE, G. O mistério de Ariana. Ed.Vega - Passagens. Lisboa, 1996. Tradução e prefácio de Edmundo Cordeiro de Morais. Rio de Janeiro: Civilização Brasileira, 2011.

FIMYAR, O. Governamentalidade como Ferramenta Conceitual na Pesquisa de Políticas Educacionais. Educação \& Realidade, v. 34(2): 35-56 mai/ago 2009.

FOUCAULT, M. A arqueologia do saber. Tradução Luiz Felipe Baeta Neves. $8^{a}$ ed. - Rio de Janeiro: Forense Universitária, 2014.

FOUCAULT, M. A ordem do discurso: a aula inaugural no Collège de France, pronunciada em 2 de dezembro de 1970, tradução Laura Fraga de Almeida Sampaio. 24ª ed. São Paulo: Edições Loyola, 2014a.

FOUCAULT, M. Microfísica do poder. Org e trad. Roberto Machado. 25a ed. Rio de Janeiro: Edições Graal, 2008.

FOUCAULT, M. Vigiar e punir. 20ª ed. Tradução de Raquel Ramalhete. Petrópolis, Vozes, 1999.

FOUCAULT, M. Ditos e escritos: Arqueologia das ciências e história dos sistemas de pensamento. MOTTA, M. B. da (org.). Tradução de Elisa Monteiro. Rio de Janeiro: Forense Universitária, v. 2, 2015.

FOUCAULT, M. Ditos e escritos: Ética, estratégia, poder-saber. In: MOTTA, M. B. da (org.). Tradução de Vera Lúcia Avellar Ribeiro. Rio de Janeiro: Forense Universitária, v. 4, 2015 a.

GREGOLIN, M. R. F. V. Formação discursiva, redes de memória e trajetos sociais de sentidos: mídia e produção de identidades. In: II Seminário de estudos de análise do discurso, 2005, Porto Alegre. II Seminário de Estudos de Análise do Discurso (CDROM). Porto Alegre, RS: UFRGS, 2005.

LEITE, J. C. C. (org.). UTFPR: uma história de 100 anos. 2ª ed. Curitiba: Ed. UTFPR, 2010.

NAVARRO, P. L. O acontecimento discursivo e a construção de identidade na História. In: SARGENTINI, V.; BARBOSA, P. L. N. (org.). M. Foucault e os domínios da linguagem: discurso, poder, subjetividade. São Carlos: Claraluz, 2004.

NAVARRO, P. L. Dispositivo e governo da velhice no discurso da WEB. Revista da ABRALIN, v. 14, p. 193-214, 2015.

NAVARRO, P. L. Práticas discursivas de subjetivação: dispositivos de análise. In PIOVEZANI

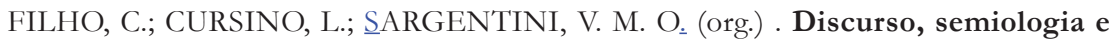
história. $1^{a}$ ed. São Carlos: Claraluz, 2011.

REVEL, J. Michel Foucault: conceitos essenciais. Tradução Maria do Rosário Gregolin, Nilton Milanez, Carlo Piovesani. - São Carlos: Claraluz, 2005.

SARGENTINI, V. M. O dispositivo: um aporte metodológico para o estudo do discurso. In: SOUSA, K.M. de. (org). Dispositivos de poder/saber em Michel Foucault: biopolítica, corpo e subjetividade. $1^{\text {a }}$ ed. São Paulo: Editora Intermeios, 2015, v.1, p. 17-27. 
UTFPR. Revista Tecnológica. Ano 1. Número 1. Abril 2015. Disponível em: <http:// www.utfpr.edu.br/estrutura-universitaria/diretorias-de-gestao/dircom/noticias/materiaisinstitucionais-da-comunicacao/revista-tecnologica-edicao-1> Acesso em: 16 jan. 2017.

VEIGA-NETO, A. Coisas de governo. In: RAGO, M.; ORLANDI, L. B. L.; VEIGANETO, A. (org.). Imagens de Foucault e Deleuze: ressonâncias nietzschianas. Rio de Janeiro: DP\&A, 2002.

VEIGA-NETO, A. Educação e governamentalidade neoliberal: novos dispositivos, novas subjetividades, 1999. Programa de apoio didático (Pad). Disponível em: <http://www. lite.fe.unicamp.br/cursos/nt/ta5.13.htm> Acesso em: 28 out. 2016.

VEYNE, P. Foucault: seu pensamento, sua pessoa. Trad. Marcelo Jacques, 2011.

VOSS, J; NAVARRO, P. A noção de enunciado reitor em Michel Foucault e a análise de objetos discursivos midiáticos. Linguagem em (Dis)curso (Online), v. 13, p. 95-116, 2013.

\section{NOTAS}

${ }^{1}$ http://legislacao.planalto.gov.br/legisla/legislacao.nsf/Viw_Identificacao/DEC\%20 7.642-2011?OpenDocument

${ }^{2}$ http://www.cienciasemfronteiras.gov.br/ Acesso em 22 nov. 2016.

${ }^{3}$ Acrescentamos o valor dos benefícios em dólares americanos uma vez que são essas quantias que aparecem no sítio do CsF para a modalidade graduação sanduíche EUA.

${ }^{4}$ Pautados em Foucault, fazemos alusão à ideia de "positividade" relacionada ao contexto histórico em que surgem verdades, tais como a que dá legitimidade ao programa o CsF, na medida em que observamos a definição de um campo enunciativo no interior do qual são desenvolvidos conceitos sobre os objetos de discurso, formas enunciativas e recorrência a temas e a estratégias que validam certa forma de falar sobre as coisas no mundo, no caso aqui tratado: a internacionalização da educação.

${ }^{5}$ Disponível em: <http://www.utfpr.edu.br/franciscobeltrao/estrutura-universitaria/ assessorias/ascom/noticias/acervo/ranking-da-folha-de-s-paulo-poe-a-utfpr-entre-as-50melhores-do-pais>.

${ }^{6}$ Nas palavras de Lemke (2007, p.17)* “a análise do governamento para Foucault combina a "microfísica do poder" que permanece centrada em questões de disciplina e normatização com a questão macro-política do Estado". * Todas as traduções da língua inglesa para a portuguesa dessa referência foram elaboradas por Carina M. Lingnau.

${ }^{7}$ A tradução livre foi realizada do inglês para o português por Carina M. Lingnau.

${ }^{8}$ De acordo com o blog de Sociologia Política de Adriano Codato (2006), o novo institucionalismo pode ser “i) instituições - e não indivíduos ou classes - são o elemento central da vida política; ii) indivíduos são 'atores' importantes, mas é mais proveitoso compreender quais são os marcos institucionais dentro dos quais eles agem, ao invés de observar o próprios indivíduos, suas motivações, preferências e escolhas (no caso, instituições funcionam como variável dependente); portanto,iii) não apenas instituições "contam" na explicação, mas são a explicação para a maior parte das ocorrências da vida política (instituições como variável 
independente)". Disponível em: <http://adrianocodato.blogspot.com.br/2009/02/o-neoinstitucionalismo-historico-uma.html> Acesso em: 20 fev. 2017.

${ }^{9}$ Disponível em: <http://www.utfpr.edu.br/franciscobeltrao/estrutura-universitaria/ assessorias/ascom/noticias/acervo/ranking-da-folha-de-s-paulo-poe-a-utfpr-entre-as-50melhores-do-pais $>$.

${ }^{10}$ Todos os documentos antigos utilizados neste trabalho não sofreram correção da grafia.

${ }^{11}$ De acordo com Novaes (2009, p.1) "A Comissão Brasileiro-Americana de Educação Industrial (CBAI) foi um programa de cooperação educacional mantido pelos governos do Brasil e dos Estados Unidos da América que iniciou suas atividades no Brasil em 1947 na capital da República, o Rio de Janeiro. Dez anos depois, mas precisamente em fevereiromarço de 1957 a CBAI transferia o Centro de Pesquisas e Treinamento de Professores para a Escola Técnica Federal do Paraná”.

${ }^{12}$ De acordo com o sítio da UTFPR “A revista Labor, lançada em abril de 1940, teve dezenove números publicados até novembro de 1947”.

${ }^{13}$ De acordo com o sítio da Biblioteca Nacional o jornal Gazeta do Rio de Janeiro foi "lançada a 10 de setembro de 1808, no Rio de Janeiro (RJ), foi o órgão oficial do governo português durante a permanência de Dom João VI no Brasil".

${ }^{14}$ modo de vida americano.

15 "Forma moderna do liberalismo, que permite uma intervenção limitada do Estado, no plano jurídico e econômico". De acordo com dicionário online, disponível em: <https:// www.dicio.com.br/neoliberalismo/>

${ }^{16}$ No texto de Veiga-Neto (1999, p.8) existe nota de rodapé: "Essa expressão é minha".

${ }^{17}$ Disponível em: < http://www.cienciasemfronteiras.gov.br/web/csf/o-programa>

${ }^{18}$ Para Foucault (2014, p. 105) o enunciado "é mais que um elemento entre outros, mais que um recorte demarcável em um certo nível de análise, trata-se, antes, de uma função que se exerce verticalmente, em relação às diversas unidades, e que permite dizer, a propósito de uma série de signos, se elas estão aí presentes ou não". Nesse trabalho não nos aprofundamos nesse conceito pois temos por objetivo refletir sobre o acontecimento e sobre o dispositivo.

${ }^{19}$ De acordo com o Correio Paulistano,’José Custódio Alves de Lima foi cônsul do Brasil em Havana e, após a Grande Guerra ( $1^{\text {a }}$ Guerra Mundial), foi cônsul geral do Brasil nos Estados Unidos."

${ }^{20} \mathrm{O}$ artigo do jornal LABOR refere-se ao momento histórico do pós-guerra (ano de publicação do jornal foi 1947).

${ }^{21}$ Disponível em < https:/ / www.youtube.com/watch?v=ZrjIeG_zGh8 > Acesso em 14 dez 2016.

${ }^{22}$ De acordo com o sítio <http://www.state.gov/100k/> “em novembro de 2009, o presidente Barack Obama anunciou o programa "100.000 Strong Iniciative" (Fortes como 100.000), um esforço nacional projetado para aumentar drasticamente o número e diversificar a composição de estudantes americanos na China". 
Submetido: $12 / 06 / 2017$

Aprovado: 15/01/2018

Contato:

Carina Merkle Lingnau

Universidade Tecnológica Federal do Paraná (UTFPR) Campus Francisco Beltrão, Linha Santa Bárbara, s/n Caixa Postal 135 Francisco Beltrão|PR |Brasil CEP 85601-970 